\title{
RESEARCH OF ENERGY SAVING MODE OF BUILDING DISTRIBUTED CONTROL SYSTEM UNDER INFLUENCE OF MANY DISTURBING FACTORS
}

\author{
Maxim N. Morozov ${ }^{1,}$, and Roman B. Ushakov ${ }^{1}$ \\ ${ }^{1}$ National Research Tomsk Polytechnic University, 634050 Tomsk, Russia
}

\begin{abstract}
A model of the building heating system, consisting of energy source, a distributed automatic control system, elements of individual heating unit and heating system is designed. Application Simulink of mathematical package Matlab is selected as a platform for the model. There are the specialized application Simscape libraries in aggregate with a wide range of Matlab mathematical tools allow to apply the "acausal" modeling concept. Implementation the "physical" representation of the object model gave improving the accuracy of the models. Advanced weather block allowed to investigate the efficiency of the control system with dynamically changing the numerous factors affecting the building energy consumption for maintaining optimal climate parameters. The conducted research of heating system and automatic control system allowed estimate efficiency of control system regulating process. The results of research of thermal condition premises, situated in the different sides of the building facade are given. The conclusions about the possibility of increasing the operational efficiency of heating system in the implementation of distributed control systems are presented.
\end{abstract}

\section{Introduction}

In recent years issues of energy conservation, improving energy and resource efficiency are considered decisive in many countries $[1,2]$.

Particular attention, as a rule, is given to activities aimed at improving the energy efficiency of administrative and industrial purposes buildings and facilities [3-9].

There are several active requirements for a modern heating system. On the one hand it is necessary to maintain the microclimate parameters at a comfortable level and on the otherit is required increasing energy efficiency of engineering building life support systems.

The aim of the present work is to investigate influence of the different type disturbing factors on the climate control system functioning and on the thermal regime and heat consumption parameters.

*Corresponding author: benm6@yandex.ru 


\section{Simulation object}

The object of research is an administration building which is located in West Siberia (Tomsk city). Heat supply of the building is carried out by a central heat supply station.

The object is the block of weather conditions, heat supply system and envelopes of the room. The heating system consists of the individual heating plant (IHP), main pipes (inlet and outlet pipes), water risers, heating appliances and control valves. The structure of the object is described in [10]. The possibility of the weather conditions variation in a wide range is the distinctive feature of the model under investigation in this paper.

Four rooms were selected in building for achieving goals of the article. All the external envelopes of one room are characterized by the same spatial orientation. Identical conditions of heat supplying are provided for heating system with parallel connection of heating appliances. For approximation to the truth operating conditions the spatial orientation of the rooms exterior wall envelopes was selected with following manner:

- room No.1 - West;

- room No.2 - South;

- room No.3 - North;

- room No.4 - East.

Rooms are characterized by identical space planning with following materials: square is $41.52 \mathrm{~m}^{2}$, volume is $112.1 \mathrm{~m}^{3}$ (figure 1 ).

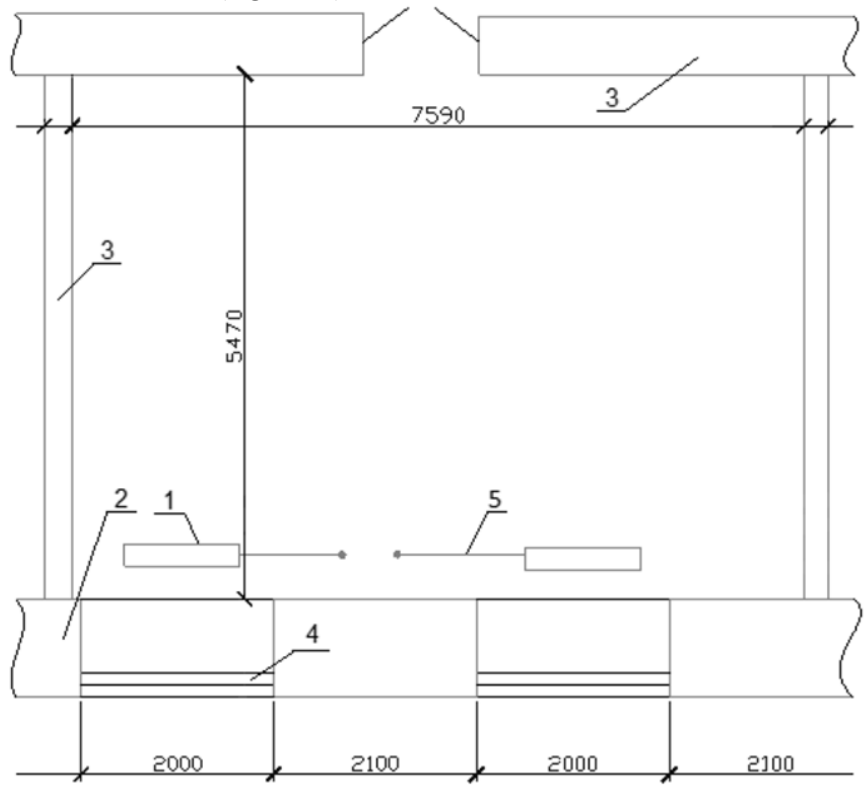

Fig. 1. A schematic illustration of simulation object (a) plan of a room, (b) axonometric scheme of the one-pipe heating system: 1 - heating appliance; 2, 3 - interior and exterior envelopes; 4 - multiple glass pane; 5 - water pipe.

Glazing ratio $\mathrm{K}_{\mathrm{gl}}$ is set to 0.23 , which corresponds to the surface area of opaque constructions $-17.85 \mathrm{~m}^{2}$ and translucent structures $-5.38 \mathrm{~m}^{2}$ (net of area of opaque multiple glass pane profile)

There is intelligent heat consumption system with distributed structure [11] were assumed: the main regulator adjusts the coolant temperature (supply and return) in IHP, local regulators adjust the individual room climate. Unique features are provided by multiloop control system of heat consumption. In this case, local control loop is limited to the physical boundaries of controlled space. The main regulator spreads to the whole building 
and interfaces technological parameters of urban heating network and heating system of building.

However, when choosing of distributed control system (DCS) [11-14], automation specialists are faced with the complicated problem of design, software synthesis and adjustment of such systems. As a rule, to solve these problems, engineers apply computer simulation models $[15,16]$. The use of computer simulation provides a small labor cost and reduces time of experimentation.

\section{Thermal model of building}

The thermal model of the building was developed to simulate operation of the heating system of the described above object. Simulink by Matlab was selected as the platform of a model. This choice is motivated by wide capabilities of software: tools to analyse system dynamics in time, connection with Workspace and other Matlab applications (for instance, Control System Toolbox), simulation of various disturbances (determined or random with different distribution laws) and situations (regular or non-regular, including emergency) which occur when in operation of the technical system. The block-oriented approach was applied to simulation and visual programming of heat supply system of building in combination with the wide range of Matlab mathematical tools. Simscape extension package which implements the concept of a "physical" simulation was also applied to develop the model [17].

Realization of the thermal model in Matlab is based on representing of each individual functional part in the form of s-functions and subsystems blocks. During simulation it is observed redistribution of heat flows between sources, medium of heat energy transfer and consumers.

\section{Modelling results}

To achieve the purpose of the present work series of numerical experiments were performed to analyze influence of selected disturbing factor on building heat consumption and thermal regimes of controlled rooms. Variations of the initial modelling data specified in Table 1.

Table 1. Initial data for modelling.

\begin{tabular}{|l|l|l|l|l|l|l|}
\hline \multirow{2}{*}{ Variable parameters } & \multicolumn{4}{|l|}{ Number of experiment } \\
\cline { 2 - 8 } & No.1 & No.2 & No.3 & No.4 & No.5 & No.6 \\
\hline Average outdoor temperature $T_{\text {out } 0},{ }^{\circ} \mathrm{C}$ & -20 & $\mathbf{- 3 0}$ & -20 & -20 & -20 & -20 \\
\hline Average flow velocity $V_{w}, \mathrm{~m} / \mathrm{s}$ & 3 & 3 & $\mathbf{4 . 5}$ & 3 & 3 & 3 \\
\hline Insolation heat gains $Q_{\text {insol }}$ & no & no & no & yes & no & no \\
\hline Internal heat sources $Q_{\text {int }}$ & no & no & no & no & yes & no \\
\hline Low heat consumption mode & no & no & no & no & no & yes \\
\hline
\end{tabular}

Values of parameters, obtained in experimental No.1, are assumed as the basic in the following experiments and changes only one by one.

Researches of influence of different types disturbing factor on heat consumption characteristics and estimation of energy saving at specialize room thermal regimes application are of particular interest for HVAC-engineers and energy managers. An estimation of heat consumption values of controlled rooms $Q_{r m i}(i=1 \ldots 4)$ was given at present work.

Table 2 shows heat consumption data of research rooms. 
Table 2. Daily heat consumption by control rooms.

\begin{tabular}{|l|l|l|l|l|}
\hline \multirow{2}{*}{ Number of experiment } & \multicolumn{3}{l|}{ Control rooms } \\
\cline { 2 - 6 } & Room No.1 & Room No.2 & Room No.3 & Room No.4 \\
\hline No.1 (basic) & 21.49 & 20.37 & 18.89 & 21.49 \\
\hline No.2 $\left(T_{\text {out }}=-30^{\circ} \mathrm{C}\right)$ & 37.47 & 36.28 & 34.42 & 37.74 \\
\hline No.3 $\left(V_{w}=4.5 \mathrm{~m} / \mathrm{s}\right)$ & 23.93 & 22.67 & 21.12 & 23.93 \\
\hline No.4 (insolation heat gains) & 20.16 & 14.44 & 18.17 & 19.65 \\
\hline No.5 (internal heat gains) & 16.76 & 15.56 & 14.01 & 16.76 \\
\hline $\begin{array}{l}\text { No.6 (energy saving thermal } \\
\text { regime) }\end{array}$ & 13.13 & 12.7 & 12.11 & 13.13 \\
\hline
\end{tabular}

Data submitted in Table 2 allow carrying out a comparative analysis. The lowest consumption of thermal energy was obtained for room No.3 (North) in the 1-st experiment. This is explained by several factors: absence of solar irradiation, wind direction (to the North). Wind load creates aerodynamic shadow on the exterior of room No.3. This reduces the value of air environment velocity along the surface of the outdoor envelopes and thus the thermal transmittance of external surface.

Comparison of experiments No.2 and No.3 provides the following results: at $50 \%$ increase of the values of $T_{\text {out }}$ и $V_{w}$ relative to the basic values (experiment No.1), the highest growth of heat consumption was obtained by carrying out an experiment No.2 (increasing of parameter $Q_{r m} 2$ was $82.2 \%$ ), whereas in experiment No.3 heat consumption increased by $11.8 \%$.

Comparison of heat gains from solar irradiation and internal heat sources (experiments No.5 and No.6 respectively), which was conducted for research object, shows a great importance of insolation influence. It should be noted a considerable spread of values of $Q_{r m i}$ for rooms with different spatial orientation: DCS provided savings $5.93 \mathrm{~kW} \cdot \mathrm{h}(29.11$ $\%$ ) in room No.2, whereas in room No.3 energy saving effect is only $0.72 \mathrm{~kW} \cdot \mathrm{h}(3.8 \%)$. In case of availability of internal heat sources energy saving attains a maximum value of 4.88 $\mathrm{kW} \cdot \mathrm{h}(25.83 \%)$ and average value of $4.79 \mathrm{~kW} \cdot \mathrm{h}(23.36 \%)$.

Experiment No.6, characterized by applying specialized thermal regimes should be noted particularly. Analysis of obtained data allows to conclude about energy conservation of $8.36 \mathrm{~kW} \cdot \mathrm{h}$ or $38.9 \%$ (in rooms No.1 and No.4). Actual value $\Delta T_{\text {in }}$ obtained for research object at $T_{\text {out } 0}=-20{ }^{\circ} \mathrm{C}$ is $2.2{ }^{\circ} \mathrm{C}$ (rooms No.1 and No.4), that can be explained by considerable value of specific thermal capacity. The same experiments at $T_{\text {out } 0}=-30{ }^{\circ} \mathrm{C}$ shows that temperature $T_{i n}$ was reduced to the value of $21{ }^{\circ} \mathrm{C}\left(\Delta T_{i n}=3{ }^{\circ} \mathrm{C}\right)$ under otherwise equal conditions.

Conducted researches allows estimating individual influence of each factor on a heat consumption and thermal regimes of controlled rooms. Multifactorial analysis play a key role in investigations of buildings thermal regimes and functioning of control systems and technological equipment. In this case simultaneous influence of many factors is taken into account and simulation conditions as realistic as possible. Figure 2 shows changing of indoor temperature $T_{i n}$ in controlled rooms in case of applying the low heat consumption mode under simultaneous influence of following factors: outdoor temperature $T_{\text {out } 0}=-30$ ${ }^{\circ} \mathrm{C}$, wind velocity $V_{w}=3 \mathrm{~m} / \mathrm{s}$, availability of solar irradiation and internal heat gains. 


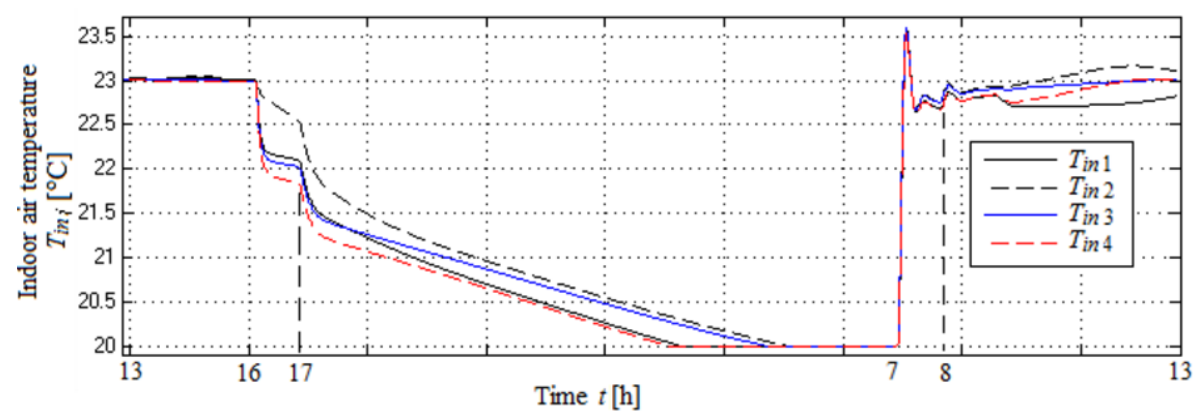

Fig. 2. Changing of indoor temperature $\mathrm{T}_{\mathrm{in}}$ in controlled rooms in case of assumed factors influence.

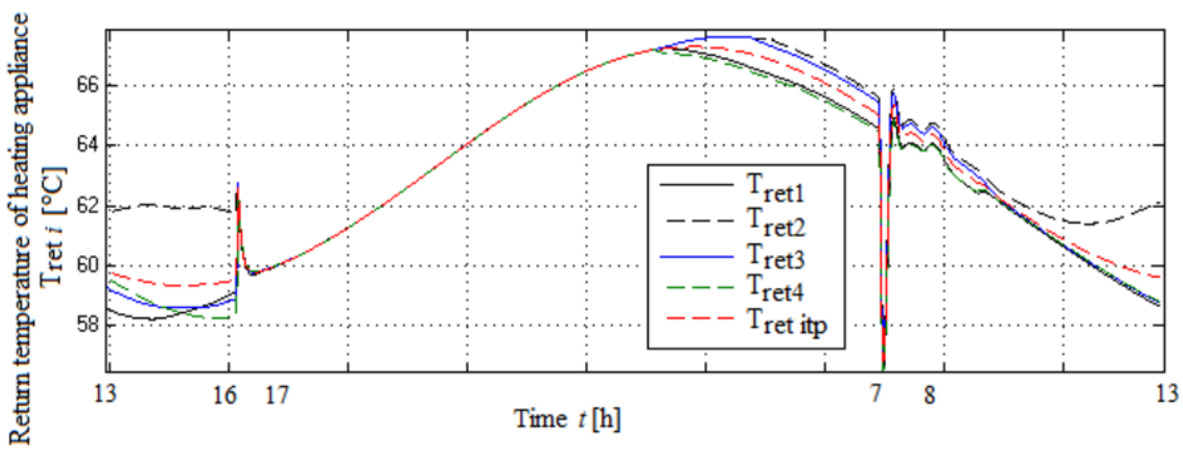

Fig. 3. Changing of return temperature of heating appliance $T_{\text {ret } i}$ and individual heating plant $T_{\text {ret itp. }}$.

Figure 2 shows possibility of realization of thermal regime (low heat consumption mode) at $\Delta T_{\text {in }}=3{ }^{\circ} \mathrm{C}$. The maximum deviation of indoor air temperature does not exceed $0.59{ }^{\circ} \mathrm{C}$ (maximum dynamic control error) from the set value of $T_{\text {in set }}=23{ }^{\circ} \mathrm{C}$. Activation of low heat consumption mode start at 16 o'clock ( 1 hour before finish a work day). It is interesting to note that specific shape of the graph caused by nulling the internal heat sources (end of work day). Further special energy saving mode is deactivated and parameter $T_{\text {in set }}$ assume a value $23{ }^{\circ} \mathrm{C}$ at 7 o'clock ( 1 hour before start a work day). Control error (deviation of $T_{\text {in }}$ from set value) does not exceed $0.05{ }^{\circ} \mathrm{C}$ in steady state operating modes.

\section{Conclusions}

Modelling for the winter climate conditions (February) of Western Siberia was conducted. Researches of heat consumption of rooms, which are characterized by different spatial orientation were conducted.

Dynamics analysis of heat consumption parameters of controlled rooms allows to conclude about the potential of energy savings that can be achieved on real object in the implementation of intelligent distributed control system of building heat consumption, that can effectively compensate all considered disturbing influences. Applying the specialize low heat consumption mode allows the energy conservation of $8.36 \mathrm{~kW} \cdot \mathrm{h}$ or $38.9 \%$ at the average outdoor temperature $-20^{\circ} \mathrm{C}$.

Distributed control system effectively compensates the deviation of indoor air temperature in case of multifactorial influence: maximum dynamic control error does not exceed 0.59 ${ }^{\circ} \mathrm{C}$ after deactivation of low heat consumption mode. 
Obtained modelling results (heat consumption, dynamic of indoor air temperature and the temperature distribution in the building envelopes) can be used to develop energy conservation measures for existing or planned buildings.

\section{Acknowledgments}

The reported study is supported by the Ministry of Education and Science of the Russian Federation Grant (project 16-38-00628).

\section{References}

1. V. Roshchanka, M. Evans, Playing hot and cold: how can Russian heat policy find its way toward energy efficiency (Pacific Northwest National Laboratory, Washington, 2012)

2. G. Keikkala, A. Kask, J. Dahl, V. Malyshev, V. Kotomkin, Energ. Policy 35, 1452 (2007)

3. A. Korppo, N. Korobova, Energ. Policy 42, 213 (2012)

4. A. Boute, Pace Envtl. L. Rev. 29, 746 (2012)

5. Z. Wang, Y. Ding, G. Geng, N. Zhu, Energy Convers. Manage. 77, 233 (2014)

6. G. Dall’O, L. Sarto, Energy Build. 67, 298 (2013)

7. G. Mustafaraj, D. Marini, A. Costa, M. Keane, Appl. Energy 130, 72 (2014)

8. T. Berger, C. Amann, H. Formayer, A. Korjenic, B. Pospischal, C. Neururer, R. Smutny, Energy and Build. 80, 517 (2014)

9. M.D. Moldovan, I. Visa, M. Neagoe, B.G. Burduhos, Energy Procedia 48, 924 (2014)

10. P. Strizhak, M. Morozov, Glavnyy energetic 7, 39 (2014)

11. R. Scattolini, J. Process Contr. 19, 723 (2009)

12. Q. Tian-Wei, H. Xiang, W. Jun-mei, Proc. Env. Sci. 11, 643 (2011)

13. P.-D.Morosan, R. Bourdais, D. Dumur, J. Buisson, Energy Build. 42, 1445 (2010)

14. F. Barata, N. Felix, R. Neves-Silva, Proc. Technology 17, 772 (2014)

15. M. Wallace, R. McBride, S. Aumi, P. Mhaskar, J. House, T. Salsbury, Chem. Eng. Sci. 69, 45 (2012)

16. S. Privara, Z. Vana, E. Zacekova, Energy and Build. 55, 341 (2012)

17. D. Broman, P. Fritzson, Proceedings of the 2nd International workshop on equationbased object-oriented languages and tools, 59 (Paphos, Cyprus, 2008) 